\title{
Characterization and evaluation of acid-modified starch of Dioscorea oppositifolia (Chinese yam) as a binder in chloroquine phosphate tablets
}

\author{
Adenike Okunlola*, Oluwatomi Akingbala \\ Department of Pharmaceutics and Industrial Pharmacy, University of Ibadan, Ibadan, Nigeria
}

\begin{abstract}
Chinese yam (Dioscorea oppositifolia) starch modified by acid hydrolysis was characterized and compared with native starch as a binder in chloroquine phosphate tablet formulations. The physicochemical and compressional properties (using density measurements and the Heckel and Kawakita equations) of modified Chinese yam starch were determined, and its quantitative effects as a binder on the mechanical and release properties of chloroquine phosphate were analyzed using a $2^{3}$ full factorial design. The nature $\left(\mathrm{X}_{1}\right)$, concentration of starch $\left(\mathrm{X}_{2}\right)$ and packing fraction $\left(\mathrm{X}_{3}\right)$ were taken as independent variables and the crushing strength-friability ratio (CSFR), disintegration time (DT) and dissolution time $\left(\mathrm{t}_{80}\right)$ as dependent variables. Acid-modified Chinese yam starch showed a marked reduction $(\mathrm{p}<0.05)$ in amylose content and viscosity but increased swelling and water-binding properties. The modified starch had a faster onset and greater amount of plastic flow. Changing the binder from native to acid-modified form led to significant increases $(\mathrm{p}<0.05)$ in CSFR and DT but a decrease in $\mathrm{t}_{80}$. An increase in binder concentration and packing fraction gave similar results for CSFR and DT only. These results suggest that acid-modified Chinese yam starches may be useful as tablet binders when high bond strength and fast dissolution are required.
\end{abstract}

Uniterms: Acid hydrolysis. Chinese yam/starch/binding properties. Factorial design. Drugs/release. Dioscorea oppositifolia/pharmaceutics.

Amido de inhame chinês (Dioscorea oppositifolia), modificado por meio de hidrólise ácida, foi caracterizado e avaliado como aglutinante em formulações de comprimidos de fosfato de cloroquina, em comparação com o amido nativo. Determinaram-se as propriedades físico-químicas e de compressão (utilizando medidas de densidade e as equações de Heckel e Kawakita). Os efeitos quantitativos do amido modificado como ligante sobre as propriedades mecânicas e de liberação de fosfato de cloroquina foram analisados por meio de um planejamento fatorial completo $2^{3}$. Tomaram-se a natureza $\left(\mathrm{X}_{1}\right)$, a concentração de amido $\left(\mathrm{X}_{2}\right)$ e a fração de empacotamento $\left(\mathrm{X}_{3}\right)$ como variáveis independentes e relação força de compressão-friabilidade (RFCE), tempo de desintegração (DT) e tempo de dissolução $\left(\mathrm{t}_{80}\right)$, como variáveis dependentes. $\mathrm{O}$ amido de inhame chinês modificado mostrou redução marcante $(\mathrm{p}<0,05)$ no teor de amilose e da viscosidade, mas aumento no inchamento e nas propriedades de ligação de água. $\mathrm{O}$ amido modificado teve início rápido e maior quantidade de fluxo plástico. A alteração do aglomerante da forma nativa para a modificada com ácido conduziu a aumento significativo $(p<0,05)$ em CSFR e DT, mas diminuição da $t_{80}$. $\mathrm{O}$ aumento da concentração do aglutinante e da fração de empacotamento deu origem a resultados semelhantes apenas para RFCE e DT. Os resultados sugerem que os amidos modificados com ácido do inhame chinês podem ser mais úteis como aglutinantes de comprimidos, quando se necessitam de força de ligação alta e de dissolução rápida..

Unitermos: Hidrólise ácida. Inhame chinês/amido/propriedades de aglutinação. Planejamento fatorial. do Fármacos/liberação. Dioscorea oppositifolia/farmacontécnica.

*Correspondence: A. Okunlola. Department of Pharmaceutics and Industrial Pharmacy, University of Ibadan, U.I. Campus Road, 200284, Ibadan, Nigeria. E-mail: templecity108@yahoo.com; adenike.okunlola@mail.ui.edu.ng 


\section{INTRODUCTION}

The use of starches as natural polymers for pharmaceutical applications remains attractive because they are cheap, readily available, biodegradable and capable of modification (Lawal et al., 2007; Yiu et al., 2008; Okunlola et al., 2010). Native starch is a white powder with a bland taste and flavor, and is insoluble in cold water. Due to the sub-optimal properties of native starches, modifications are efficient methods of improving their suitability as excipients for specific pharmaceutical uses. Physical modification entails subjecting the starch to heat-moisture treatment and annealing, while chemical modification includes oxidation, acid thinning, hydroxypropylation and acetylation. Starches have been chemically modified by acid hydrolysis for over 150 years (Yiu et al., 2008). This process involves suspending starch in an aqueous solution of hydrochloric acid or sulphuric acid at certain temperatures. In the presence of strong acid and heat, the glycosidic bonds between the monosaccharides in the starch polymer are cleaved (Yiu et al., 2008). Acid modification has been shown to change the physicochemical properties of starch without destroying its granular structure, yielding starch with increased solubility and gel strength but decreased viscosity; the extent of hydrolysis depends on starch consistency, the acidity of the medium, the hydrolysis temperature and the duraton of hydrolysis (Odeku et al., 2009).

Although the effects of acid hydrolysis of various starches, such as corn, potato and rice starches, have been studied (Wang, Wang, 2001; Wang et al., 2003; Thirumthavorn, Charavenrein, 2005), acid modification of starches from other botanical sources may yield compounds with a wide range of functional properties permitting numerous applications. Native starch obtained from Dioscorea oppositifolia (Chinese yam; family Dioscoreaceae) has been shown to produce tablets of high mechanical strength when used as binders (Okunlola, Odeku, 2009). When modified by acid hydrolysis, this starch showed potential as a directly compressible excipient for controlled release (Odeku et al., 2009). To our knowledge, the relative efficacy of acid-modified Chinese yam starch as a binding agent in tablet formulations for pharmaceutical use has not been assessed. Therefore, the suitability of acid modified starch of Dioscorea oppositifolia (Chinese yam) as binding agent in chloroquine tablet formulation was determined in comparison to the native form of the starch. Chloroquine phosphate, an important antimalarial drug, has poor compression properties and requires a binding agent among other excipients to form satisfactorily strong tablets.

\section{MATERIAL AND METHODS}

\section{Material}

Chloroquine phosphate BP and corn starch BP were obtained from BDH Chemicals Ltd. (Poole, UK), and lactose from DMV (Veghel, Netherlands). Tubers of Chinese yam (Dioscorea oppositifolia (L.) were obtained from local farmers in Ibadan, Nigeria, and authenticated. The starches were extracted using established methods (Young, 1984).

\section{Preparation of acid-modified starch}

Three hundred grams (dry basis) of native Dioscorea starch were hydrolyzed by incubating the starch in $600 \mathrm{~mL}$ $6 \% \mathrm{HCl}$ solution at $23 \pm 1{ }^{\circ} \mathrm{C}$ for 192 hours without stirring (Atichokudomchai, Varavinit, 2003). The suspension was neutralized with $10 \%(\mathrm{w} / \mathrm{v}) \mathrm{NaOH}$ solution, and the starch slurry was washed five times with distilled water and dried in a hot air oven at $40{ }^{\circ} \mathrm{C}$ for 24 hours. The starch was powdered with a laboratory ball mill operated at $1425 \mathrm{rpm}$ (GEC Machines Ball mill BS 220 6H, Newcastle, England) and passed through a $125 \mu \mathrm{m}$ mesh sieve.

\section{Amylose content determination}

The amylose content of the starches was determined using the colorimetric method as described (Williams et al., 1970). One hundred $\mathrm{mg}$ of sample was transferred to a $100 \mathrm{~mL}$ volumetric flask, to which was added $1 \mathrm{~mL} 95 \%$ ethanol and $9 \mathrm{~mL} 1 \mathrm{~N} \mathrm{NaOH}$. The sample was heated for 10 minutes in a boiling water bath to gelatinize the starch, cooled and made up to volume with water. A 5-mL portion of starch solution was transferred to a $100-\mathrm{mL}$ volumetric flask, to which was added $1 \mathrm{~mL} 1 \mathrm{~N}$ acetic acid and $2 \mathrm{~mL}$ iodine solution, and the volume was made up to $100 \mathrm{~mL}$ with distilled water. The solution was shaken for $20 \mathrm{~min}$ and the absorbance at $620 \mathrm{~nm}$ was determined using a UV/VIS spectrometer (Phillips Pye Unicam, PU 8610 Kinetics, Sarose Scientific Instruments, Cambridge, UK).

\section{Swelling power and water binding capacity}

Swelling power was determined as described (Bowen, Vadino, 1984). Starch was suspended at 5\% $(\mathrm{w} / \mathrm{w})$ by shaking at room temperature for 5 minutes. The dispersion was allowed to stand for 24 hours before the sedimentation volume was measured and the swelling capacity was calculated

Water binding capacity was determined as described 
(Ring, 1985). Five g of starch were placed in a $100 \mathrm{~mL}$ measuring cylinder, which was made up to $100 \mathrm{~mL}$ with deionized water while shaking. The dispersion was centrifuged (Centrifuge TDL 80-2, Bombay, India) for 25 minutes at $5000 \mathrm{rpm}$. The supernatant was discarded, the residue weighed, and the water-binding capacity was calculated.

\section{Viscosity profiles of starches}

The viscosity profiles of the starches were assessed using a Rapid Visco-Analyzer (RVA, Serial-3, Newport Scientific, NSW, Australia) coupled with Thermocline for Windows software. Three $\mathrm{g}$ starch were dispersed in $25 \mathrm{~mL}$ distilled water in the viscometer test canister. The slurry was heated at a constant shear rate, and the increase in viscosity of the material was measured as torque on the spindle. The time-temperature regimen used was $50{ }^{\circ} \mathrm{C}$ for $1 \mathrm{~min}$, heating from $50^{\circ} \mathrm{C}$ to $95^{\circ} \mathrm{C}$ in $3.75 \mathrm{~min}$, and holding at $95^{\circ} \mathrm{C}$ for $2.50 \mathrm{~min}$. The sample was subsequently cooled to $50{ }^{\circ} \mathrm{C}$ over $3.75 \mathrm{~min}$ and maintained at $50{ }^{\circ} \mathrm{C}$ for $2 \mathrm{~min}$ (Thiewes, Steeneken, 1997).

\section{Determination of precompression density}

The bulk density of each starch powder at zero pressure (loose density) was determined by pouring $30 \mathrm{~g}$ of the powder at an angle of $45^{\circ}$ through a funnel into a glass measuring cylinder with a diameter of $24 \mathrm{~mm}$ and a volume of $50 \mathrm{~mL}$ (Itiola, 1991). The relative density $\mathrm{D}_{\mathrm{o}}$ of each starch was obtained from the ratio of its loose density to its particle density.

\section{Compaction data analysis}

Quantities (500 mg) of starch powder were compressed for 30 seconds into tablets with predetermined loads on a Carver hydraulic press (Model C, Carver Inc. Menomonee Falls, WI) using a $10.5 \mathrm{~mm}$ die and flat-faced punches lubricated with a $1 \%$ dispersion of magnesium stearate in acetone before each compression. The compression equations of Heckel and Kawakita were used to assess the compaction properties of the starches (Heckel, 1961a, 1961b; Kawakita, Ludde, 1970, 1971; Odeku, Itiola, 1998).

\section{Preparation of granules}

Batches (200 g) of a basic formulation of chloroquine phosphate $(60 \% \mathrm{w} / \mathrm{w})$, lactose $(30 \% \mathrm{w} / \mathrm{w})$ and corn starch $(10 \% \mathrm{w} / \mathrm{w})$ were dry mixed for 5 minutes in a planetary mixer (Model A120, Hobart Manufacturing Co, UK) and moistened with appropriate amounts of starch paste to produce granules containing $5.0 \%(\mathrm{w} / \mathrm{w})$ and $10.0 \%$ $(\mathrm{w} / \mathrm{w})$ of the starches as binder. Massing was continued for 5 minutes and the wet masses were granulated by passing them manually through a 12 mesh sieve $(1400 \mu \mathrm{m})$, followed by drying in a hot air oven at $50^{\circ} \mathrm{C}$ for 18 hours. The dried granules were sieved through a 16 mesh sieve $(1000 \mu \mathrm{m})$ and stored in an air tight container.

\section{Preparation of tablets}

Tablets $(500 \mathrm{mg})$ were prepared from the $500-1000 \mu \mathrm{m}$ size fractions of granules by compressing them for 30 seconds with predetermined loads on a Carver hydraulic hand press (Model C, Carver Inc., Menomonee Falls, WI, USA). The $10.5 \mathrm{~mm}$ die and flat-faced punches were lubricated with a $1 \% \mathrm{w} / \mathrm{v}$ dispersion of magnesium stearate in acetone. After ejection, the tablets were stored over silica gel for 24 hours. The weights (w) of ten tablets and their dimensions were measured within $\pm 1 \mathrm{mg}$ and $0.01 \mathrm{~mm}$, respectively, and their relative densities (D) were calculated using the equation:

$$
\mathrm{D}=\mathrm{w} / \mathrm{V}_{\mathrm{t}} \rho_{\mathrm{s}} \quad \text { Eq. } 1
$$

where $V_{t}$ is the volume $\left(\mathrm{cm}^{3}\right)$ of the tablet and $\rho_{s}$ is the particle density $\left(\mathrm{gcm}^{3}\right)$ of the solid materials.

\section{Determination of mechanical properties}

Crushing strengths of the tablets were determined at room temperature by diametral compression using a hardness tester (Ketan Scientific and Chemicals, Ahmedabad, India). The percent friability of the tablets was determined using a friabilator (Veego Scientific Devices, Mumbai, Maharashtra, India) operated at $25 \mathrm{rpm}$ for 4 minutes.

\section{Determination of release properties}

The disintegration time of the tablets was determined in distilled water at $37 \pm 0.5^{\circ} \mathrm{C}$ using a disintegration tester (Veego Scientific). Dissolution tests on the tablets were performed using the USPXX III basket (Hanson Model 72RL, U.S.A) rotated at $100 \mathrm{rpm}$ in $900 \mathrm{~mL}$ of $0.1 \mathrm{M}$ HCL and maintained at $37 \pm 0.5{ }^{\circ} \mathrm{C}$. Samples $(5 \mathrm{~mL})$ were withdrawn and replaced with equal amounts of fresh medium. Each sample was diluted and the amount of chloroquine phosphate released was determined spectrophotometrically at $255 \mathrm{~nm}$, using a UV/visible 
spectrophotometer (Phillips Pye Unicam, PU 8610 Kinetics, Sarose Scientific Instruments, Cambridge, UK).

\section{Full factorial design}

Three factors, each at two different levels, were selected and experimental trials were performed using all eight possible combinations (Gohel, Amin, 1998). In the present study, the nature of starch $\left(\mathrm{X}_{1}\right)$, concentration of starch $\left(\mathrm{X}_{2}\right)$ and packing fraction $\left(\mathrm{X}_{3}\right)$ were chosen as the independent variables and crushing strength friability ratio (CSFR), disintegration time (DT) and dissolution times $\left(\mathrm{t}_{80}\right)$ as dependent variables. A comprehensive study of the effects of these process parameters and their interactions was carried out with the aid of suitable statistical software (Minitab 14.2).

\section{Statistical analysis}

Each experiment was performed in triplicate and the mean determined. The effects of starches on tablet properties were compared using analysis of variance (ANOVA) on GraphPad Prism ${ }^{\odot} 4$ computer software (Graphpad Software Inc. San Diego, CA, USA), with the Tukey-Kramer multiple comparison test used to compare differences between the starches. At 95\% confidence intervals, $p$ values less than or equal to 0.05 were considered significant.

\section{RESULTS AND DISCUSSION}

The physicochemical properties of the native and acid-modified Dioscorea starches are shown in Table I and compared with the properties of corn starch. Amylose content was greater in corn starch than in Chinese yam starch and greater in native than in acid-modified Chinese yam starch. The swelling capacity of the starches at room temperature $\left(27 \pm 2{ }^{\circ} \mathrm{C}\right)$ was greater for acid-modified Chinese yam starch than for corn starch, which was greater than for Chinese yam starch, and water-binding capacity was greater for acid-modified than for native Chinese yam starch, with the latter greater than that of corn starch. The amylose content of modified starch was significantly less $(p<0.05)$ than that of native starch due to the destruction of the starch helical structure during hydrolysis, which reduces the amount of amylose-iodine complex. Swelling power provides evidence for the magnitude of interactions between starch chains within amorphous and crystalline domains. The swelling power of starch is dependent on its amylopectin content (Tester, Morrison, 1990; Singh et al., 2011). Water penetration into the starch granules of modified Chinese yam starch increased due to its increased hydrophilicity, which resulted in its rapid swelling. Thus, acid treatment of Dioscorea starch produced slurries with higher swelling power and greater water-binding capacity.

The viscosity profiles of the starches are presented in Figure 1. These profiles reflect the changes in starches during heating and cooling in the Rapid Visco-Analyser (RVA). The initial increase in viscosity as the granules begin to swell is due to the onset of gelatinization (Yadav et al., 2006). Starch viscosity increases during the cooling phase due to gelling, and has been attributed to the retrogradation of starch molecules (Guha, Bhattacharya,

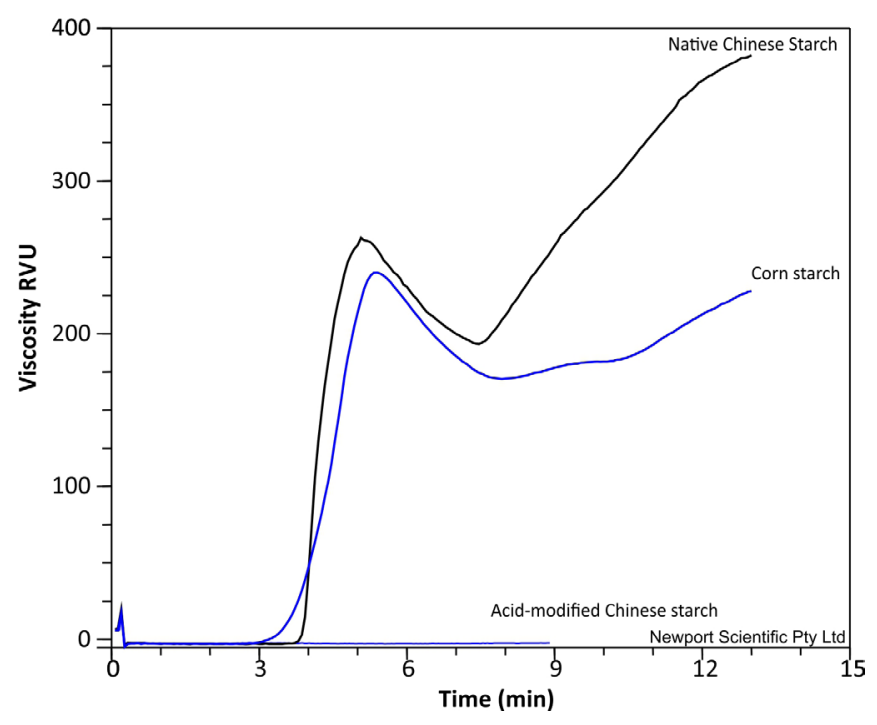

FIGURE 1 - Viscosity profile of starches.

TABLE I - Physicochemical properties of the starches (Mean $\pm \mathrm{SD}, \mathrm{n}=4)$

\begin{tabular}{lcccccc}
\hline Starch & $\begin{array}{c}\text { Granule size } \\
(\mu \mathrm{m})\end{array}$ & $\begin{array}{c}\text { Amylose content } \\
(\%)\end{array}$ & $\begin{array}{c}\text { Particle Density } \\
\left(\mathrm{g} \mathrm{cm}^{-3}\right)\end{array}$ & $\begin{array}{c}\text { \% Solubility } \\
\left(27^{\circ} \mathrm{C}\right)\end{array}$ & $\begin{array}{c}\text { Swelling power } \\
\left(27^{\circ} \mathrm{C}\right)(\mathrm{v} / \mathrm{v})\end{array}$ & $\begin{array}{c}\text { Water binding } \\
\text { capacity }(\mathrm{g} / \mathrm{g})\end{array}$ \\
\hline Native Chinese & $7.40 \pm 0.36$ & $21.61 \pm 1.50$ & $1.51 \pm 0.01$ & $1.04 \pm 0.02$ & $0.82 \pm 0.04$ & $1.15 \pm 0.04$ \\
Acid-modified & $3.95 \pm 0.55$ & $15.33 \pm 0.12$ & $1.55 \pm 0.00$ & $5.22 \pm 0.42$ & $1.55 \pm 0.02$ & $2.50 \pm 0.03$ \\
$\begin{array}{l}\text { Chinese } \\
\text { Corn }\end{array}$ & $14.60 \pm 2.58$ & $27.20 \pm 0.08$ & $1.49 \pm 0.01$ & $1.10 \pm 0.01$ & $1.20 \pm 0.03$ & $0.95 \pm 0.03$ \\
\hline
\end{tabular}


TABLE II - Rheological properties of the starches (Mean $\pm \mathrm{SD}, \mathrm{n}=4)$

\begin{tabular}{lcccc}
\hline Starch & Peak viscosity $(\mathrm{RVU})$ & Peak Time $(\mathrm{min})$ & Pasting Temperature $\left({ }^{\circ} \mathrm{C}\right)$ & Final Viscosity $(\mathrm{RVU})$ \\
\hline Native Chinese & $262.92 \pm 2.97$ & $5.74 \pm 0.35$ & $84.90 \pm 0.96$ & $382.33 \pm 1.04$ \\
Acid-modified Chinese & $-4.83 \pm 0.22$ & $4.40 \pm 0.24$ & $90.25 \pm 0.70$ & $-5.17 \pm 0.11$ \\
Corn & $240.00 \pm 1.08$ & $5.43 \pm 0.13$ & $88.55 \pm 0.87$ & $227.83 \pm 1.61$ \\
\hline
\end{tabular}

1998). The viscosity parameters of corn starch and native and acid-modified Chinese yam starch are shown in Table II. The peak viscosity, defined as the maximum viscosity achieved during or soon after the heating portion of the test, was higher for native Chinese yam than for corn starch, which in turn was higher than that of acid modified Chinese yam starch. The negative values obtained for the acid-modified starches suggest that acid modification results in marked reduction $(\mathrm{p}<0.05)$ in starch viscosity, similar to previous findings (Pessa et al., 2006; Hamit et al., 2007). The ranking of final viscosity, a direct measure of the viscosity of the gel formed after retrogradation, was in the same order, indicating that the gelling properties of Dioscorea starch weakened as a result of acid hydrolysis.

Heckel plots of $\ln [1 /(1-\mathrm{D})]$ against applied pressure (P) (where $\mathrm{D}$ is the relative density at pressure $\mathrm{P}$ ) were plotted for the two starches (Figure 2). The mean yield pressure, $\mathrm{P}_{\mathrm{y}}$, was calculated from the portion of the plots showing the highest correlation coefficient $\geq 0.990$ for all the formulations. The mean yield pressure, $\mathrm{P}_{\mathrm{y}}$, for the formulations are shown in Table III. $\mathrm{P}_{\mathrm{y}}$ was inversely related to the ability of the formulation to deform plastically under pressure and was greater for native than for acid-modified Chinese yam starch, indicating that the latter showed faster onset of plastic deformation during compression than the native form. The rate of deformation may be very important in tableting, since most tableting machines have short dwell or compression times. This finding thus suggests that acid-modified Dioscorea starch may be more useful in formulations compressed on high speed tablet machines with short dwell time.

The volume of each starch at zero pressure was determined using the equation:

$$
\mathrm{V}_{\mathrm{o}}=\pi \mathrm{r}^{2} \mathrm{~h}
$$

where $r$ is the radius of the cylinder and $h$ is the height of the sample. The volumes of the starch tablets at different compression pressures, $\mathrm{V}_{\mathrm{p}}$, were also calculated. The degree of volume reduction, $\mathrm{C}$, was calculated from the equation:

$$
\mathrm{C}=\left(\mathrm{V}_{\mathrm{o}}-\mathrm{V}_{\mathrm{p}}\right) / \mathrm{V}_{\mathrm{o}}=\mathrm{abP} /(1+\mathrm{bP})
$$

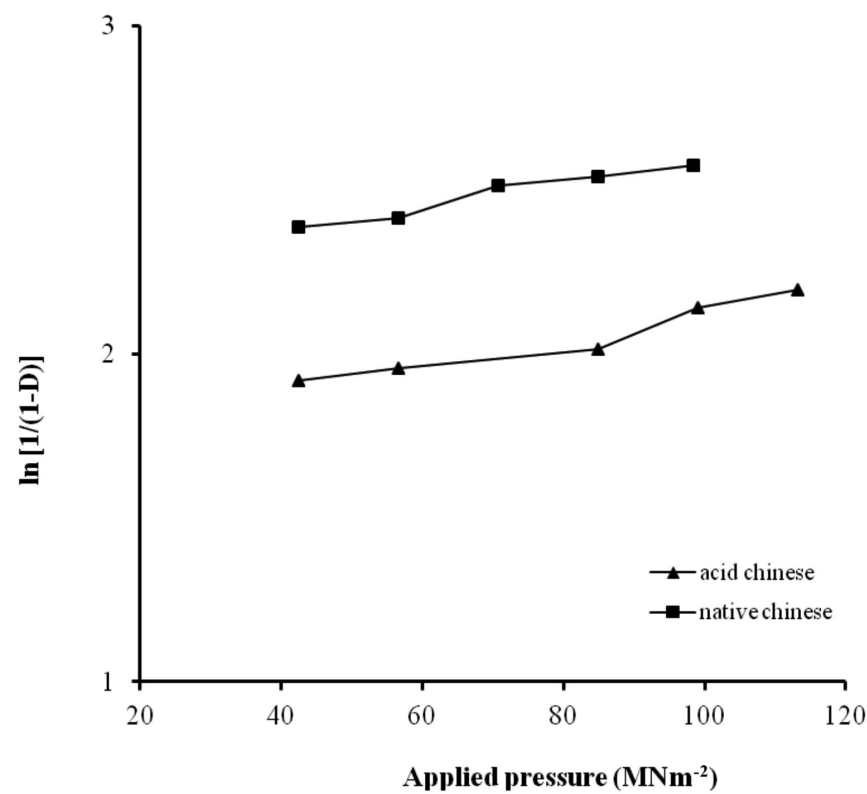

FIGURE 2 - Heckel plots for starches.

TABLE III - Parameters derived from density measurements and from the Heckel and Kawakita plots

\begin{tabular}{lccc}
\hline Starch & Do & $\mathrm{P}_{\mathrm{y}}\left(\mathrm{MNm}^{-2}\right)$ & $\mathrm{P}_{\mathrm{k}}\left(\mathrm{MNm}^{-2}\right)$ \\
\hline Native Chinese & 0.314 & 416.67 & 1.384 \\
Acid-modified & 0.303 & 277.78 & 2.483 \\
\hline
\end{tabular}

Kawakita plots of $\mathrm{P} / \mathrm{C}$ against the applied pressure, P, were plotted for the starches (Figure 3). A linear relationship was observed at all compression pressures used, with a correlation coefficient of 0.999 for all starches. The $P_{k}$ value, which is an inverse measurement of the amount of plastic deformation occurring during the compression process (Odeku, Itiola, 1998), is also presented in Table III. The $\mathrm{P}_{\mathrm{k}}$ value was lower for acidmodified than for native Chinese yam starch. Since a lower $\mathrm{P}_{\mathrm{k}}$ value is correlated with greater total plastic deformation during compression (Odeku, Itiola, 1998; Podczeck, Sharma, 1996), acid-modified Chinese yam starch exhibited a greater amount of total plastic deformation. The combination of the two methods usually provides a more accurate analysis of the compaction behavior of 
TABLE IV - Factorial design for the formulation and evaluation of batches

\begin{tabular}{lccccccccc}
\hline \multirow{2}{*}{$\begin{array}{l}\text { Batch } \\
\text { code }\end{array}$} & \multicolumn{3}{c}{ Coded levels } & \multicolumn{3}{c}{ Real values } & \multirow{2}{*}{ CSFR } & DT (min) & $\mathrm{t}_{80}(\mathrm{~min})$ \\
\cline { 2 - 6 } & $\mathrm{X}_{1}$ & $\mathrm{X}_{2}$ & $\mathrm{X}_{3}$ & $\mathrm{X}_{1}$ & $\mathrm{X}_{2}(\%)$ & $\mathrm{X}_{3}(\%)$ & & & 15.00 \\
$\mathrm{~B}_{1}$ & -1 & -1 & -1 & Native & 5.00 & 0.80 & 15.79 & 4.00 & 11.50 \\
$\mathrm{~B}_{2}$ & +1 & -1 & -1 & Acid-modified & 5.00 & 0.80 & 45.10 & 5.80 & 1000 \\
$\mathrm{~B}_{3}$ & -1 & +1 & -1 & Native & 10.00 & 0.80 & 18.18 & 7.00 & 39.00 \\
$\mathrm{~B}_{4}$ & +1 & +1 & -1 & Acid-modified & 10.00 & 0.80 & 88.24 & 14.00 & 13.50 \\
$\mathrm{~B}_{5}$ & -1 & -1 & +1 & Native & 5.00 & 0.90 & 138.70 & 9.20 & 25.00 \\
$\mathrm{~B}_{6}$ & +1 & -1 & +1 & Acid-modified & 5.00 & 0.90 & 518.18 & 12.60 & 23.00 \\
$\mathrm{~B}_{7}$ & -1 & +1 & +1 & Native & 10.00 & 0.90 & 148.57 & 26.00 & 43.00 \\
$\mathrm{~B}_{8}$ & +1 & +1 & +1 & Acid-modified & 10.00 & 0.90 & 1500.00 & 28.00 & 26.00 \\
\hline
\end{tabular}

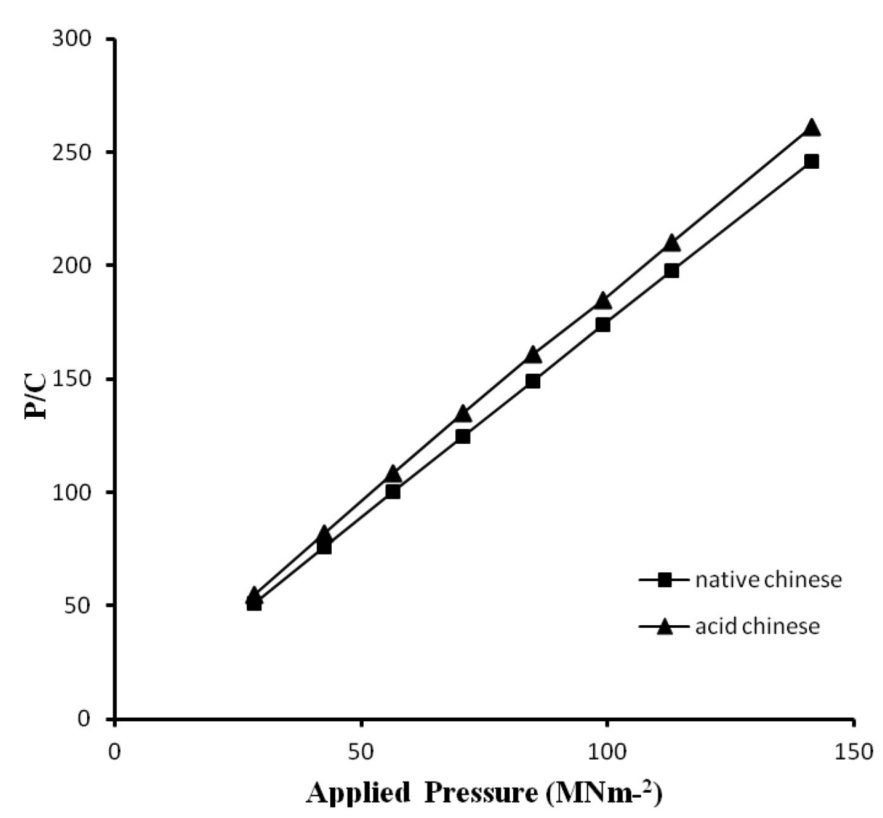

FIGURE 3 - Kawakita plots for starches.

pharmaceutical materials since the Kawakita equation appears to show linearity at low pressure while the Heckel equation generally shows linearity at high pressure. Increased compression speed is correlated with decreased compact density and a corresponding increase in the material's mean yield pressure, due to the time-dependent nature of plastic deformation. Since plastic deformation is time-dependent (Rees, Rue, 1978; Akande et al., 1998), the rate of plastic flow may be more important than the total plastic flow in producing tablets with acceptable mechanical strength.

It is desirable to develop acceptable pharmaceutical formulations in the shortest possible time using minimal efforts and raw materials. Factorial design can result in an appropriate mathematical model with a minimum number of experiments required for optimization of formulation design. This allows all factors to be varied simultaneously, thus enabling evaluation of the effects of each variable at each level as well as showing the interrelationships among them. The values of CSFR, DT and $t_{80}$ for the factorial experiments are presented in Table IV. The full factorial experimental design provides a clear indication of the quantitative effects of three parameters on three response variables; i.e., the nature of starch $\left(\mathrm{X}_{1}\right)$, the concentration of starch $\left(\mathrm{X}_{2}\right)$ and the packing fraction $\left(\mathrm{X}_{3}\right)$. The values of the individual and interaction coefficients are presented in Table V. The relative magnitudes of the effects of the factors on these variables can be observed, as a positive effect shows an increase in the magnitude of the response value while a negative effect shows a decrease.

TABLE V - Summary of the individual and interaction coefficients of the variables on the Crushing Strength Friability Ratio (CSFR), Disintegration Time (DT) and dissolution times $\left(t_{80}\right)$ of chloroquine phosphate tablets containing native and acid-modified starches

\begin{tabular}{lcccc}
\hline Factor & Coefficient & CSFR & DT $(\mathrm{min})$ & $\mathrm{t}_{80}(\mathrm{~min})$ \\
\hline $\mathrm{X}_{1}$ & Effect & 228.8 & 1.775 & -6.00 \\
& p-value & 0.300 & 0.227 & 0.092 \\
$\mathrm{X}_{2}$ & Effect & 129.7 & 5.425 & 5.875 \\
& p-value & 0.466 & 0.096 & 0.094 \\
$\mathrm{X}_{3}$ & Effect & 267.3 & 5.625 & 4.750 \\
& p-value & 0.261 & 0.093 & 0.116 \\
$\mathrm{X}_{1} \mathrm{X}_{2}$ & Effect & 126.60 & 0.475 & -4.625 \\
& p-value & 0.473 & 0.667 & 0.119 \\
$\mathrm{X}_{1} \mathrm{X}_{3}$ & Effect & 203.90 & -0.425 & 1.250 \\
& p-value & 0.330 & 0.697 & 0.389 \\
$\mathrm{X}_{2} \mathrm{X}_{3}$ & Effect & 118.30 & 2.625 & -0.625 \\
& p-value & 0.495 & 0.194 & 0.605 \\
\hline
\end{tabular}


All coefficients were positive for the influence of the nature of starch $\left(\mathrm{X}_{1}\right)$, the concentration of starch $\left(\mathrm{X}_{2}\right)$ and the packing fraction $\left(\mathrm{X}_{3}\right)$ on CSFR. A positive coefficient indicates that changing the binder from native to acid-modified Chinese yam starch results in tablets of higher mechanical strength, suggesting that acid-modified Chinese yam starch has better binding properties than the native form. Acid hydrolysis is known to preferentially attack the amorphous regions of the starch granule while leaving crystalline regions intact, resulting in stronger packing under compression pressure (Tuschoff, 1986) and explaining the increase in tablet strength of formulations containing acid-modified starches. Moreover, an increase in starch concentration from $5 \%$ to $10 \%$ resulted in an increase in CSFR. The availability of more contact points between particles as the concentration of starch binder increases results in the formation of solid bonds producing tablets with more resistance to fracture and abrasion. Similarly, an increase in packing fraction from low to high (i.e. from 0.80 to 0.90 ) produced tablets of higher CSFR. The ranking of the coefficients was in the order $\mathrm{X}_{3}>\mathrm{X}_{1}>\mathrm{X}_{2}$ on CSFR, showing that packing fraction was the most significant variable affecting tablet hardness. This was expected, as the packing fraction of a pharmaceutical material increases as compression pressure increases. Increased compression pressure results in a decrease in porosity or a reduction in capillary microstructure of the tablets (Itiola, Pilpel, 1986), resulting in closer packing. Thus, more solid bonds will be formed between the particles, which in turn will lead to an increase in the mechanical strength of the tablets.

All coefficients were positive for the influence of all variables on DT. An increase in starch binder concentration results in the formation of solid bonds, which may result in a longer disintegration time. Increased compression pressure will increase the packing fraction of a pharmaceutical material, decreasing the porosity and reducing the size of the capillary spaces between the particles. This will reduce the rate of penetration of water, increasing disintegration time. The ranking of the coefficients was in the order $\mathrm{X}_{3}>\mathrm{X}_{2}>\mathrm{X}_{1}$ on DT, showing that packing fraction was the most significant variable affecting disintegration time while the nature of the starch had the least effect.

The coefficients were positive for the influence of $\mathrm{X}_{2}$ and $\mathrm{X}_{3}$, but negative for the influence of nature of starch, $\mathrm{X}_{1}$ on $\mathrm{t}_{80}$. Thus, changing the type of binder from native to acid modified Chinese yam starch produced chloroquine phosphate tablets that dissolved faster. A higher starch binder concentration results in the formation of solid bonds, which may lead to longer disintegration times.
However, the high degree of swelling of the acid-modified starch resulted in an increased rate of water penetration, reducing dissolution times. The ranking of the coefficients was in the order $\mathrm{X}_{1}>\mathrm{X}_{2}>\mathrm{X}_{3}$ on $\mathrm{t}_{80}$ with the nature of starch having the greatest effect on tablet dissolution time.

The values of the interaction coefficients are presented in Table $\mathrm{V}$. The ranking for CSFR was $\mathrm{X}_{1} \mathrm{X}_{3}$ $>X_{1} X_{2}>X_{2} X_{3}$, indicating that the interaction between the nature of starch and the packing fraction $\left(\mathrm{X}_{1} \mathrm{X}_{3}\right)$ had the greatest effect on CSFR. The ranking for DT was $\mathrm{X}_{2} \mathrm{X}_{3}$ $>\mathrm{X}_{1} \mathrm{X}_{2}>\mathrm{X}_{1} \mathrm{X}_{3}$, indicating that the interaction between binder concentration and packing fraction had the greatest influence on disintegration time. Positive values indicated that the variables interacted to increase the CSFR and DT of the chloroquine tablets. The interaction between nature of starch and binder concentration had the most influence on $t_{80}$ as the ranking was $X_{1} X_{2}>X_{1} X_{3}>X_{2} X_{3}$. The negative values of interaction between the nature of starch and its concentration indicate that the variables interacted to reduce dissolution time. A similar effect was observed for the interaction between concentration of binder and packing fraction. Packing fraction $\left(\mathrm{X}_{3}\right)$ appears to interact with all the variables. This is expected as $\mathrm{X}_{3}$ had the largest individual effect on the mechanical property (CSFR) and release (DT) of the tablets. Taken together, these results suggest that acid modified Chinese yam starch may be a better binder than native starch, providing greater mechanical strength but faster dissolution of tablets. These results also show that increasing the binder type and concentration of the tablets would increase CSFR and DT. Thus, there is a need to carefully choose the type and

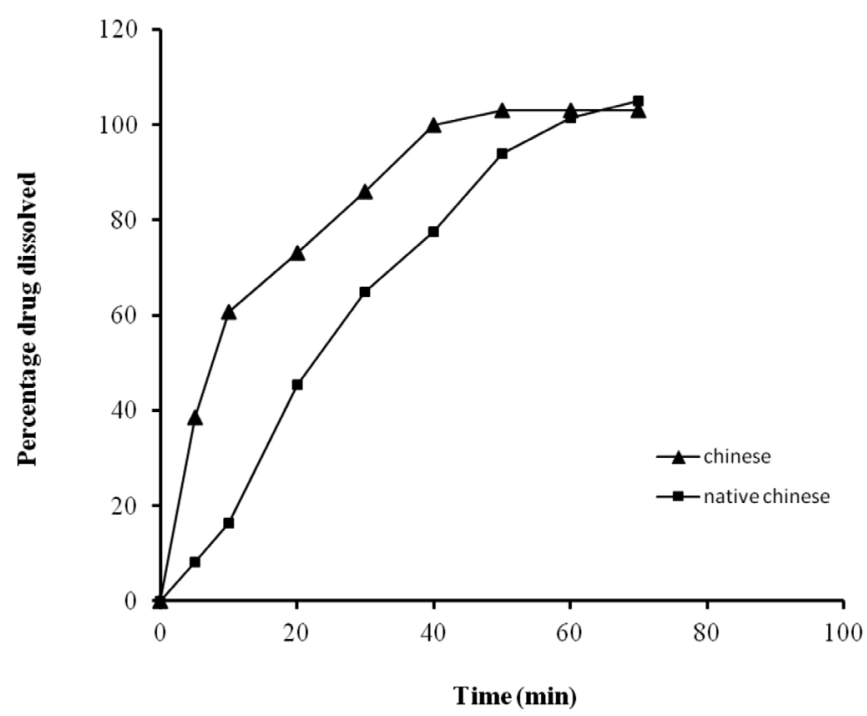

FIGURE 4 - Percentage chloroquine phosphate released over time for tablet formulations containing $10 \% \mathrm{w} / \mathrm{w}$ of starch binder at a packing fraction of 0.90 . 

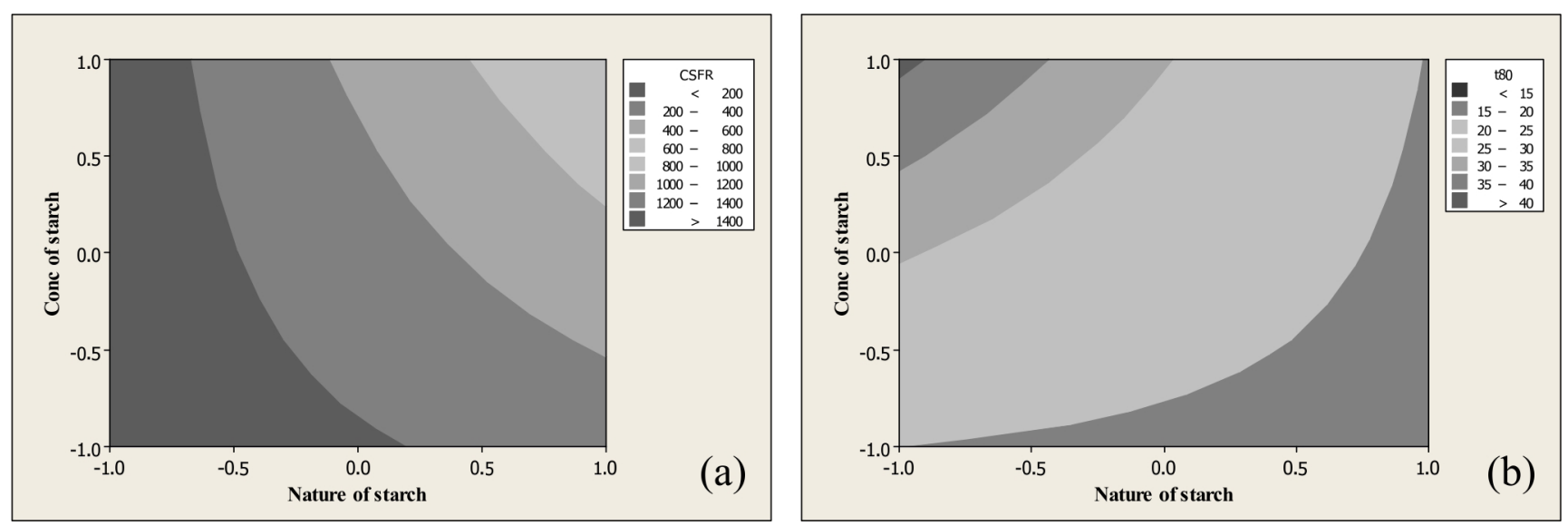

FIGURE 5 - Contour plots of (a) crushing strength friability ratio (CSFR) and (b) dissolution time $\left(\mathrm{t}_{80}\right.$ ) of chloroquine phosphate tablets as a function of the nature of starch and the concentration of starch.

concentration of starch binder utilized in a formulation, to produce tablets with an adequate balance between mechanical strength and drug release properties.

Contour plots were drawn by coding the values of the nature and concentration of starch (Figure 5), while keeping the variable packing fraction constant. A contour plot is a graphic representation of the relationships among three numeric variables in two dimensions. Two variables are plotted on the $\mathrm{x}$ and $\mathrm{y}$ axes, and the third variable $\mathrm{z}$ is used for contour levels. The contour levels are plotted as curves; the area under the curve is color coded to indicate interpolated value. Contour plots can be used to predict relevant responses as they show the relative effects of the variables on the responses. Figures 5(a) and (b) show the effects of the nature of starch and polymer concentration on CSFR and $t_{80}$, respectively. The dark grey region in each plot shows that starch concentration had a greater effect than the nature of starch on the mechanical properties of chloroquine phosphate formulations. In contrast, the contour plots for $\mathrm{t}_{80}$ showed that the nature of starch had a greater effect on the dissolution of the formulations.

\section{CONCLUSION}

The results presented here provide some insight into the effectiveness of Dioscorea oppositifolia starch in its native and acid-modified forms as binders in chloroquine tablet formulations. Acid hydrolysis reduced granule size, amylose content, and viscosity while increasing swelling power. Our results also showed that acid-modified Chinese yam starches had a faster onset of plastic flow under compression pressure than the native form of the starch. The pharmaceutical characteristics of chloroquine phosphate tablets are significantly affected by the nature of the starch binder, the concentration of the binder and the packing fraction. Acid-modified Chinese yam starch produced tablets with stronger mechanical properties but shorter dissolution times than the native Dioscorea starch, indicating that acid-modified Dioscorea starches may be more useful than the native forms as binding agents, especially when higher mechanical strength and faster dissolution rates are desired. These results suggest a positive outlook for using modified Chinese yam starch in tablet formulations and for its commercial exploitation.

\section{REFERENCES}

AKANDE, O.F.; FORD, J.L.; ROWE, P.H.; RUBINSTEIN, M.H. The effects of lag time and dwell time on the compaction properties of 1:1 paracetamol/microcrystalline cellulose tablets prepared by pre-compression and main compression. J. Pharm. Pharmacol., v.50, p.19-28, 1998.

ATICHOKUDOMCHAI, N.; VARAVINIT, S. Characterization and utilization of acid-modified cross linked tapioca starch in pharmaceutical tablets. Carbohydr. Polym., v.53, p.263270, 2003.

BOWEN, F.E.; VADINO, W.A. A simple method for differentiating sources. Drug Dev. Ind. Pharm., v.10, p.505-51, 1984.

GOHEL, M.C.; AMIN, A.F. Formulation optimization of controlled release diclofenac sodium microspheres using factorial design. J. Controlled Release, v.51, p.115-122. 1998.

GUHA, M.; ALI, S.Z.; BHATTACHARYA, S. Effect of barrel temperature and screw speed on rapid viscoanalyser pasting behaviour of rice extrudate. Int. J. Food Sci.Technol., v.33, p.259-266, 1998. 
HAMIT, K.; ARZU, B.; KEVSER, K.; SERPIL, O. Effect of acid modification and heat treatments on resistant starch formation and functional properties of corn starch. Int. J. Food Prop., v.4, p.691-702, 2007.

HECKEL, R.W. An analysis of powder compaction phenomena. Trans. Metall. Soc. AIME, v.221, p.1001-1008, 1961 b.

HECKEL, R.W. Density- pressure relationships in powder compaction. Trans. Metall. Soc. AIME, v.221, p.671-675, 1961 a.

ITIOLA, O.A.; PILPEL, N. Tableting characteristics of metronidazole formulations. Int. J. Pharm., v.31, p.99-105, 1986.

ITIOLA, O.A. Compression characteristics of three starches and the mechanical properties of their tablets. Pharm. World J., v.8, p.91-94, 1991.

KAWAKITA, K.; LUDDE, K.H. Some considerations on powder compression equations. Powder Technol., v.4, p.61-68, 1970, 1971.

LAWAL, O.S.; LECHNER, M.D.; HARTMANN, B.; KULICKE, W.M. Carboxymethyl cocoyam starch: synthesis characterization and influence of reaction parameters. Starch/Stärke, v.59, p.224-233, 2007.

ODEKU, O.A.; ITIOLA, O.A. Evaluation of khaya gum as a binder in a paracetamol tablet formulation. J. Pharm. Pharmacol., v.4, p.183-188, 1998.

ODEKU, O.A.; SCHMID, W.; PICKER-FREYER, K.M. Characterization of acid-modified Dioscorea starches as direct compression excipients. Pharm. Dev. Technol., v.14, p.259-270, 2009.

OKUNLOLA, A.; PATEL, R.P.; ODEKU, O.A. Evaluation of freeze-dried pregelatinized Chinese yam (Dioscorea oppositifolia) starch as a polymer in gastroretentive metformin microbeads. J. Drug Del. Sci. Tech., v.20, p.457$465,2010$.

OKUNLOLA, A.; ODEKU, O.A. Formulation factors affecting the binding properties of Chinese yam (Dioscorea oppositifolia) and corn starches. J. Tropic. Med., v.2, p.17, 2009.
PESSA, E.; LIS, P.; SUORTTI, T.; AUTIO, K.; POUTANEN, $\mathrm{K}$. Molecular weight characterization and gelling properties of acid-modified maize starches. Starch/Stärke, v.44, p.6469, 2006.

PODCZECK, F.; SHARMA, M. The influence of particle size and particle shape of components of binary powder mixtures on the maximum volume reduction due to packing. Int. J. Pharm., v.137, p.41-47, 1996.

REES, J.E.; RUE, P.J. Time dependent deformation of some direct compression excipient. J. Pharm. Pharmacol., v.30, p.601-607, 1978.

RING, S.G. Some studies on gelatin. Starch/Stärke, v.37, p.80$87,1985$.

SINGH, A.V.; NATH, L.K.; GUHA, M.; KUMAR R. Microwave assisted synthesis and evaluation of crosslinked carboxymethylated Sago starch as superdisintegrant. Pharmacol. Pharm., v.2, p.42-46, 2011.

TESTER, R.F.; MORRISON, W.R. Swelling and gelatinization of cereal starches. Effect of amylopectin, amylose and lipids. Cereal Chem., v.67, p.551-557, 1990.

THIEWES, H.J.; STEENEKEN, P.A.M. Comparison of the Barbender Viscograph and the Rapid Visco-Analyser. 1. A statistical evaluation of pasting profiles. Starch/Stärke, v.49, p.85-92, 1997.

THIRATHUMTHAVORN, D.; CHARAVENREIN, S. Thermal and Pasting properties of acid-treated rice starch. Starch/ Stärke, v.57, n.5. p.217-222, 2005.

TUSCHOFF, J.V. Hydroxypropylated starches. In: WURZBURG, O.B. (Ed.). Modified starches: properties and uses. Boca Raton: CRC Press, 1986. p.89-96.

WANG, L.; WANG, Y.J. Structures and physicochemical properties of acid-thinned corn, potato and rice starches. Starch/Stärke, v.53, p.570-576, 2001.

WANG, Y.J.; TRUONG, V.D.; WANG, L. Structures and rheological properties of corn starch as affected by acid hydrolysis. Carbohydr. Polym., v.52, p.207-217, 2003.

WILLIAMS, P.C.; KUZINA, F.D.; HLYNKA, I. A rapid calorimetric procedure for estimating the amylose content of starches and flours. Cereal Chem., v.47, p.411-420, 1970. 
YADAV, A.R.; GUHA, M.; THARANATHAN, R.N.; RAMTEKE, R.S. Changes in characteristics of sweet potato flour prepared by different drying techniques LWT. Food Sci. Technol., v.39, p.20-26, 2006.

YIU, P.H.; LOH, S.L.; RAJAN, A.; WONG, S.C.; BONG, C.F.J. Physicochemical properties of sago starch modified by acid treatment in alcohol. Am. J. Appl. Sci., v.5, p.307-311, 2008.
YOUNG, A.H. Fractionation of starch. In: WHISTLER, R.L.; BEMILLER, J.N.; PASHALL, E.F. (Eds.). Starch Chem. Technol., 2ed. London: Academic Press, 1984. p.249-283.

Received for publication on $25^{\text {th }}$ July 2012 Accepted for publication on $22^{\text {nd }}$ February 2013 